\title{
EL SEDUCTOR CASTIGADO EN LA COMEDIA DE BRETÓN DE LOS HERREROS
}

\author{
Miguel Ángel MURO \\ Universidad de La Rioja \\ miguel-angel.muro@unirioja.es
}

\section{1}

\section{La omnipresente figura del seductor en el teatro del XIX}

Leyendo el teatro de buena parte del siglo XIX en España no sería difícil llegar a la impresión de que la sociedad burguesa estaba siendo atacada o, al menos, amenazada en sus fundamentos por una legión de seductores dispuestos a acabar con la honra de las mujeres, el matrimonio y la familia: tantas son las tramas de seducción que presentan esas obras, tanto en drama como en comedia. No parece, sin embargo, que fuera así (o que fuera más que en otras épocas), pero esas tramas y el personaje que amenaza la honra, el matrimonio y la unión entre los cónyuges sintetizaban bien, de forma atractiva y potente, los temores de desórdenes que el liberalismo y el romanticismo producían a los miembros de una burguesía inmovilista y de moral católica tridentina. El personaje masculino apasionado hasta el delirio y la muerte que estaba siendo entronizado en el drama romántico no es, en la mayoría de las obras, propiamente un seductor (un cínico que juega con los sentimientos y deseos de una o varias mujeres para engañarlas), pero su acción disolvente sobre la honra, el matrimonio o la familia es la misma porque imposibilita o disuelve los lazos religiosos y sociales. Tras él, pero ya en la estela de Félix de Montemar, vendrá el libertino, desprovisto de cualquier aura «romántica», ceñido a la seducción implacable de la mujer, lindante con el burlador, aquel que seduce a la mujer queriendo, además, burlarse de ella, engañarla, de forma cínica, sin que importe el dolor ni la situación afectiva, familiar o social en que quede cuando es deshonrada.

Bretón de los Herreros toma al seductor como objeto de su sátira para desposeerlo de cualquier atractivo fascinador (Argullol, 1982: 59-60) y desactivar así su posible efecto pernicioso en la proba sociedad burguesa para la que escribe. La serie de comedias en que lleva a cabo esta acción recorre el centro del siglo: comienza con Me voy de Madrid (1836), donde no era difícil ver un ataque a Larra, y acaba con el propio final de su carrera teatral con El abogado de pobres (1866). La suya es, por tanto, (como ocurre con otros aspectos de aquella sociedad que refleja en sus obras) una mirada relevante, muy marcada tanto artística como ideológicamente que remite a otras propuestas previas y corre paralela a algunas otras muy relevantes a lo largo del siglo XIX. Casi al tiempo que el personaje de 
Tirso estaba convirtiéndose en un mito en la obra de Molière, Mózart-Da Ponte y Byron, a la espera de Zorrilla (Becerra, 1997), Bretón llevaba a cabo una tarea contraria a la mitificación, intentando frenarla e impedirla.

\section{El peligroso atractivo del seductor}

$\mathrm{El}$ arquetipo del seductor de mujeres se remonta al sustrato folklórico de la humanidad y puede tener su primera manifestación literaria potente en Ulises, como señala Rodríguez Adrados. Para este helenista, «toda enseñanza y también toda libertad, toda creación, ha salido de la Fiesta; allí está el origen de todo el pensamiento, de toda la literatura» (1972: 490). La Fiesta implica la primacía de la Risa vital, la eclosión de la vitalidad no sujeta a normas que van a encarnar en Grecia los cultos dionisíacos.

El héroe del mito es complejo y no armonioso; en sus cualidades y actuación tienen importancia la magia, el erotismo, la violencia sexual, la violación, el incesto, el miedo, la prepotencia, el engaño, el robo, el sacrilegio o la irreverencia ante los dioses. Cuando este héroe del mito y de la épica pasa al teatro, la tragedia tiende a filtrar los componentes negativos, buscando la ejemplaridad, mientras la comedia los acoge como propios porque pretende mantener la energía de la Fiesta ritual y de su Risa, recuperar algo de la libertad y de la felicidad perdidas por la institución del orden y las leyes.

Parte de esa vitalidad carnavalesca se mantiene todavía en La Celestina de Rojas, heredera de la comedia latina, pero su final funesto ya es una advertencia sobre los peligros de las pasiones desmedidas y, a medida que se va asentando la concepción cristiana del mundo, con su moral estricta, la comedia que triunfa es la que define Cicerón como «espejo de costumbres y maestra de la vida» preocupada por enseñar antes que por divertir y, por supuesto, alejada de cualquier desmán orgiástico.

El burlador de Sevilla o El convidado de piedra de Tirso (1630) recupera como drama la figura del seductor y engañador de mujeres, noble altanero, asocial, caracterizado también por su irreverencia religiosa que paga con la condenación eterna, y su esquema ideológico es seguido a las puertas del Romanticismo por Antonio de Zamora en No hay plazo que no se cumpla ni deuda que no se pague y Convidado de piedra. La condición disolvente del don Juan de Tirso se pule y acera de forma brillante por Espronceda en su poema El estudiante de Salamanca (1837-1840). Don Félix de Montemar es el hombre satánico (en el sentido de que Dios solo consigue doblegarlo con la muerte; porque, por otro lado, desafía al propio Diablo y se pone a su nivel y al de Dios) y titánico (su estatura humana supera a la de cualquier mortal y, además, se acrecienta porque no se da ninguna explicación psicológica de sus tremendos actos, dejando que el lector sospeche que es porque no podría soportar su negrura). Es inmoral, cínico, depravado, dominador, altanero, burlador y pendenciero, homicida sin escrúpulo alguno y cruel; es energía destructiva pura pero también energía incontenible para romper las trabas (de cualquier tipo, humanas, como el amor y el honor, y divinas) y perseguir cualquier novedad, cualquier reto, aun a riesgo de su vida y de su alma. Don Félix (y don Juan Tenorio después) es un burlador y es también, y más aún, un buscador que intenta escudriñar el misterio y hasta la esencia de 
Dios («el hombre en fin que en su ansiedad quebranta / su límite a la cárcel de la vida, / y a Dios llama ante él a darle cuenta, / y descubrir su inmensidad intenta» (vss. 1245-1260); en este sentido, importa también mucho el que sea un jugador empedernido, porque será capaz de jugarse todo sin que importe el valor de lo jugado ni el riesgo que corre con ello: el dinero, el retrato de su amada, su propia vida, su condenación eterna. Es un «corazón gastado» un hombre aquejado del hastío profundo de la vida, que hace preferir las flores del mal, al aburrimiento mortal de una vida sin alicientes, que se verá en otros héroes románticos. Pero hay que subrayar que hay objetos distintos en la búsqueda de estos héroes: el don Juan de Byron busca el ideal de forma incansable, el don Félix de Montemar busca la novedad, el riesgo, el reto, por sí mismos. Don Félix es la primera encarnación en España del hombre romántico, el que afronta el misterio con orgullo despreciando la ayuda de Dios; el primer paso para prescindir de Dios.

Las gentes de orden de las clases medias españolas sufrieron el escándalo y experimentaron la atracción y el temor a los héroes de los dramas románticos para quienes ningún lazo, ni humano ni divino, tenía entidad suficiente como para oponerse o desafiar a su pasión. La declaración de principios de Macías en el drama de Larra («Los amantes son solos los esposos»), unida al incesto parricida de Alfredo en el de Pacheco fueron aldabonazos en la moral y conciencia cívica de los espectadores que basaban su concepción social en la estabilidad inquebrantable del matrimonio y la familia, protegida por sacramentos y leyes.

En todos estos casos (incluido El Burlador de Sevilla) es innegable el aura atractiva que posee el protagonista, como representante de quien rompe las normas familiares, sociales y religiosas y deja atisbar una vida intensa de riesgo, desorden, libertad y placer. La muerte y el castigo divino lejos de atenuar o borrar el atractivo contribuye a dotarlos de una dimensión sobrehumana, de titanes, de ángeles caídos que se enfrentan a un Dios, engrandecidos de forma trágica en la asunción previa de la derrota y el castigo.

\section{Respuestas desactivadoras del tipo de burlador de mujeres}

El Don Juan Tenorio de Zorrilla (1844) es la respuesta conservadora a la amenaza disolvente del héroe romántico, aún dentro del Romanticismo y aprovechando el drama romántico, su fórmula estética e ideológica más representativa. Zorrilla amalgamó en estado de gracia creativo las cualidades del burlador de mujeres, del retador de hombres y del ser humano que relativiza y desdeña el poder divino. Dispuesto a desactivar su hechizo, el autor lo convirtió en enamorado decidido a sentar cabeza y en retador capaz de humillarse para pedir disculpas. El fracaso de su primera intención, rubricado con los homicidios del Comendador y de Mejía y un exabrupto contra el Cielo, lo deja en disposición de despeñarse en el abismo (como el don Álvaro de Rivas), pero Zorrilla prefiere conducirlo al desengaño, al choque con las postrimerías, al fracaso y muerte en duelo y, como apoteosis, a la salvación por amor (o por caridad cristiana), todo un itinerario modélico de reforma (o reinserción social) y redención para réprobos, ovejas descarriadas, calaveras o hijos pródigos (dejando, eso sí, al 
margen la libertad con que el autor trata asuntos teológicos y que el pecador se arrepiente en el último instante de su vida más por miedo que por fe verdadera).

Pero no es fácil desactivar o deslustrar un mito que toca a la pasión y la muerte porque algunos de sus motivos pueden brillar aislados, en sí mismos. Así, en esta creación de Zorrilla aún cabía la posibilidad de que espectadores y espectadoras se dejaran ganar por el gusto de la transgresión, por el hechizo de amores extraordinarios, como se ve en La Regenta, donde Ana Ozores ve plasmado en la escena el ideal del amor que ella desea con afán y que le será dado en forma de un donjuán provinciano y algo machucho. Ello, claro está, suponía fraccionar la obra, desgajando el final del resto, con lo que eso supone de reorientación ideológica (de vuelta a las obras representativas del romanticismo liberal). Y hay otro aspecto más que tener en cuenta, que tiene que ver, en este caso, con la supuesta tendencia maternal de la mujer a redimir al réprobo, aun a costa de su sufrimiento e infelicidad. La Pamela de Richardson (1740) ya había mostrado la grandeza y beneficios de la virtud femenina en el ejemplo de la joven, hermosa y virtuosa dama de compañía que, resistiendo el acoso del libertino para quien trabaja, consigue llegar a ser amada por él y a rubricar su dicha con un venturoso matrimonio. Bien es cierto que el señor de B. se comporta como un libertino más que paciente, nada drástico, y que Pamela -en la primera parte de la novela, la más atractiva- aun en los momentos de mayor asedio no puede dejar de sentir algo parecido a atracción por su decidido y obsesivo seductor.

Acto seguido del Don Juan Tenorio de Zorrilla, la reacción contra lo que esta figura aún tenía de disolvente de los principios conservadores de la sociedad del momento, a pesar de su conversión in extremis, viene de la mano del también conservador Ventura de la Vega con El hombre de mundo (1845), ya fuera del ámbito del drama romántico, por medio de una comedia seria que abre las puertas a la denominada «alta comedia» (Díez Taboada, 1997, Muro, 2003), donde el libertino ya ha perdido cualquier componente satánico (además, por supuesto, del motivo de la cena de los muertos y el convidado de piedra), y se ha aburguesado y casado felizmente. Pero de la Vega considera que los crímenes no prescriben y hace del escarmiento ejemplar del seductor el objetivo principal de su obra. Ventura de la Vega hace padecer a su protagonista el intento de seducción de su esposa por parte de un antiguo compañero de correrías, con la angustia añadida de verse reflejado en él, de saber el proceso y los posibles resultados. La propuesta contra el donjuanismo en esta obra es radical porque llega a querer eliminar el pasado del seductor reformado (Muro, 2003: 1963). El tejado de vidrio (1856) de Adelardo López de Ayala, sigue esta línea ideológica apoyada en la máxima de «donde la dan las toman», aquí trasladada a otra cercana: «Quien tiene el tejado de vidrio no ha de arrojar piedras contra el de su vecino».

La enorme popularidad del Tenorio de Zorrilla y su acusada teatralidad convirtieron a la obra en atractivo objeto de parodia, buena forma de privar al personaje asocial de su aura atractiva. Es lo que ocurre con la chocarrera Juan el perdío (1848) de Mariano Pina y Boñigas y de otras muchas de esta laya a lo largo del siglo (Crespo, 1979; Serrano, 1995). Adelardo López de Ayala llevó a cabo una parodia de más fuste y enjundia en El nuevo don Juan (1863), convirtiendo al seductor casi en un 
personaje de farsa, haciéndolo esconderse bajo una mesa o pasar buena parte de un acto oculto en un armario, como si de Catalinón se tratara y no de Don Juan.

\section{Los seductores en el teatro de Bretón: el seductor serio y el chisgarabís}

Bretón, por su parte, recorre todo el arco de estas obras a lo largo de la mayor parte del siglo XIX y presenta una respuesta en clave de comedia a la peligrosa figura del seductor (romántico o no), desposeyendo al tipo de cualquier connotación sobrehumana y reduciéndolo a la condición de ciudadano de a pie cuando no a la de mero chisgarabís. De Macías o don Álvaro se desciende primero a un don Juan sin estrella ni magia ni blasfemia ni grandeza, y de él a un don Luis Mejía (avant le personnage) sin la épica chulesca del desafío, el listado acumulativo de crímenes ni el riesgo de la muerte. Los seductores del teatro de Bretón son ciudadanos de andar por casa, en su mayor parte convertidos, incluso cuando tienen alguna entidad malvada, en espantajos ridículos y cobardes, miserables que han de ser desenmascarados y expuestos a la vergüenza pública para escarmiento de cualquiera que pretendiera emularlos. Suponen la vacuna o la revancha de una sociedad burguesa medrosa, timorata e hipócrita contra un peligro (Casalduero, 1974: 150). El seductor va contra la piedra angular del orden social, la familia, y también del orden religioso (inextricablemente unido con el social y el político en la España del momento), en la medida en que se opone al matrimonio como sacramento e institución social y, piensa Bretón, es necesario presentarlo en las tablas sin un ápice de atractivo y, bien al contrario, exhibiendo su bajeza moral (Marrast, 1989: 633).

Hay en estas comedias una seducción afectiva cuya finalidad es el goce sexual de la mujer engañada (goce apenas insinuado) y hay otra que es económica, crematística, que persigue la dote de la mujer. Hay seductores con algún empaque de predadores, pocos; la gran mayoría son mequetrefes de poca entidad que anticipan en alguna medida las parodias más risibles del Don Juan Tenorio.

Me voy de Madrid (1836) causó la irritación de Larra por la tosca y malévola sátira que hacía de él Bretón con quien hasta el momento había mantenido una buena relación. El protagonista de la obra es don Joaquín, un personaje endeudado, temido por sus sátiras, y vendido al Gobierno de turno; un cínico «seductor impío» que, tras seducir a Amparo, una prendera ambulante, se aprovecha de los tópicos románticos sobre la pasión para encandilar a Manuela, una viuda que se cree a pies juntillas el romanticismo tópico (aunque antes de nada exija palabra de matrimonio), de la que vende su retrato, y que intenta hacer otro tanto con Tomasa, casada sensata y tradicional, con la que fracasa («... poner lascivos ojos / en mujer que tiene dueño», II, viii ${ }^{1}$; «Presume usted de famoso / libertino, á lo que veo; / pero en esto de mujeres / no hay seguro reglamento, / que suele dar la más boba / lecciones á los maestros», II, viii). No hay sino cualidades negativas y desagradables en la confección de este tipo en absoluto épico (en el crimen solo llega a asustar a un acreedor con una pistola descargada) a quien se castiga sin piedad dejándolo en ridículo ante todos hasta hacerlo salir huyendo de Madrid, corrido y

\footnotetext{
${ }^{1}$ Todas las citas textuales de las comedias de Bretón se hacen de la edición de Bretón de los Herreros (1883-1884) que aparece en la bibliografía.
} 
despavorido, no sin que antes haya sido acosado por un sastre acreedor, amenazado por un marido furioso, frustrado por un cambio de gobierno que lo deja sin prebendas y desenmascarado por sus dos conquistas, una de las cuales amenaza con perseguirlo hasta el fin del mundo para convertirse en su esposa.

En la comedia en un acto El hombre pacífico (1838) el seductor pasa a ser un personaje secundario y de poco fuste, como ocurrirá después en otras obras. El protagonismo queda en este caso para don Benigno, el hombre pacífico, cuya paciencia proverbial es puesta a prueba por varios y variados inconvenientes entre los que sobresale la pendencia que tienen en su casa y ante él su hermana, $\mathrm{D}^{\mathrm{a}}$ Ramona, «jamona» y Casilda, joven tontamente romántica, por D. Mamerto, chisgarabís que en su día sedujo a la mayor con palabra de matrimonio, dejándola plantada («Diez años ha que me dio / palabra de casamiento; / huyó después el malvado / y no he vuelto a verle el pelo / hasta anoche...»), y pasa por el mal trago de encontrarlas juntas, de soportar sus insultos y reproches, viéndose obligado a huir («Piés, para qué os quiero?», se dice), como en la comedia anterior.

En otra obra estrenada el mismo año, Flaquezas ministeriales (1838), son dos los seductores y, por primera vez, esta figura es tratada por Bretón sin ninguna concesión cómica. El primer seductor es un personaje secundario, Pereda, que añade al cinismo afectivo y sexual del seductor el del chantaje a la mujer a la que burló tiempo atrás y que en el comienzo de la obra es, con identidad falsa de condesa, la amante de un ministro inmoral a quien maneja. Pereda, el seductor, después de amenazar a Violante con revelar sus secretos si no logra del ministro una prebenda, rechaza con un aplomo considerable la acusación de seducción que le hace la mujer, repartiendo las culpas del hecho: «Violante, / dejémonos de parodias / sentimentales. Nacimos / ambos á dos, no lo ignoras, / con propensión admirable / yo á ser tuno, tú a ser loca. / Yo aborrecía los libros, / y tú la aguja y la escoba. / Yo hidalgo pero sin bienes; / Tú plebeya, pero hermosa; / yo emprendedor, tú coqueta; / yo barbilindo, tú moza; tu espejo por una parte / y mi ociosidad por otra..., / los dos perdimos a un tiempo, Violante, la poca cholla / que nos quedaba, y ni tú / puedes acusarme ahora / de seductor, ni aplaudirme / debo yo de la victoria» (I, i). A las quejas de la mujer de haber sido robada y abandonada después por el seductor, él replica que el quebranto no debió ser grande ya que ella se consoló pronto con el cónsul de Liorna. El castigo que recibirá pereda será el de perder el cargo cuando ya lo creía en su mano y ser deportado por la policía a América. El segundo seductor es el propio Marqués que, aun fascinado por Violante, intenta otra conquista en la hija de una solicitante de su ministerio. Lo novedoso en este caso es que sea un criado suyo el que lleve la embajada a la muchacha deseada y reciba en pago una buena tunda por parte del novio que relata así el episodio: «[El Marqués] ha querido seducir / a mi adorada Ramira. / Se introdujo en vuestra casa / un agente de sus vicios. / no es mucho; tales servicios / se suelen premiar sin tasa. / Aventuro su osadía / la infame proposición / que con casta indignación / rechazó la prenda mía. / Porfiaba temerario / llego entonces, oigo, acudo / y fue mi primer saludo / un puntapié al emisario. / Entónces el perillán / me amenazó con su amo, / y de un tramo en otro tramo / le eché rodando al zaguán» (II, xv). El castigo del Marqués es perder el ministerio por la intriga del Barón en quien confiaba y al mismo tiempo a Violante a quien también recluyen fuera de la corte. 
D. Agustín, el seductor de la comedia en tres actos Un día de campo o El tutor y el amante (1839) pretende a la joven e inexperta Sabina, sobrina de don Antonio, el tutor al que alude el título, enamorado también de la muchacha. El enredo sentimental se acentúa con la acción de $\mathrm{D}^{\mathrm{a}}$ Celedonia, señora entrada en años y tía también de Sabina que, queriendo pescar a D. Antonio, ayuda al seductor. Por supuesto que también en este caso, como en los anteriores, el seductor es desenmascarado; aquí el tutor lo pone ante la perspectiva de que la muchacha vaya al matrimonio sin dote y queda de manifiesto que era el dinero lo que lo movía. Ante la insistencia apasionada de Sabina para seguir adelante con su amor en la pobreza (que recuerda a Contigo pan y cebolla de Gorostiza), Agustín declara que: «La medianía / es soportable, convengo; / pero la indigencia tiene / una cara que da miedo. / Si tú sola fueses pobre, / no repararía en eso, / pero yo lo soy también, / y nada y nada... son cero. / Si nos casamos los dos / tú te pierdes, yo me pierdo, / y échale un galgo á la dote! [...] Renuncio pues á tu mano. [...] Y harto lo siento; / mas, si no mi bien, el tuyo / reclama tamaño esfuerzo / de mi corazón amante; / porque eso del menosprecio / de las riquezas, y el bosque, / y el pájaro y el insecto, / son famosos materiales / para hacer bonitos versos, / pero el estómago... En fin, / lo dicho, dicho y laus Deo» (III, xi). Seductor de clase media: prosaísmo y bajeza moral.

En la comedia en cuatro actos ;Una vieja! (1839), Bretón vuelve al esquema del cínico y, a la postre, chusco seductor de varias mujeres al mismo tiempo que acabará ridiculizado cuando se descubra su juego. En este caso se trata de don Alberto quien pretende a $\mathrm{D}^{\mathrm{a}}$ Luisa, viudita pedantuela, y a Jacinta, una joven ingenua, y cuyo interés crematístico quedará descubierto por la tía de Jacinta, $\mathrm{D}^{\mathrm{a}}$ Damiana, vieja rica, «zumbona y alegre» que consigue que don Alberto se le declare a ella también sin saber que sus otras dos conquistas lo están escuchando. De nuevo se pone de manifiesto que el peso mayor en la seducción tiene que ver con el dinero de las mujeres: «Procedes como hombre bajo», como «hombre ruin», le dirá Jacinta cuando el donjuán, tentado por la oferta económica mejor de la vieja, rechace la propuesta perentoria de matrimonio que la muchacha le hace. Cuando su juego es descubierto, se retira de la escena tratando de mantener el tipo con alguna dignidad, manifestando que se le da un ardite lo sucedido pero los apartes explicitan el chasco que se ha llevado y la irritación que le produce: «Me colgaría de un árbol. [...] Me llevan los diablos. [...] Reniego de mi fortuna. [...] El tifus me va a dar si no me sangro» (IV, $\mathrm{x}$ ).

La seducción de índole solamente sexual se plantea de forma algo descarnada en la comedia en dos actos Pruebas de amor conyugal (1840) donde D. Cayetano, rico («con el oro que recaudo / puedo llenar un falucho», I, v), planea seducir a Paula, joven esposa sin experiencia en el cuidado del hogar ni en calibrar la diferencia entre la galantería cortés y las intenciones torcidas de los hombres; como dice en aparte el seductor, burlándose de la hipocresía de su discurso: «¿Quién ha visto a un libertino / hecho fraile recoleto?» (I, v). Al privilegio que da el dinero y la posición, el seductor sumará (como en el Don Juan Tenorio) la ayuda cómplice, y venal, de la criada de Paula, quien justifica con un interesante y descarado cinismo su actitud: «Es preciso tener cara / de vaqueta y de vinagre / para negarse á servir / á sujeto tan amable. / La conciencia me remuerde / un poco; mas treinta reales / de salario mal seguro, / y sin provechos ni gajes, / ¿qué son para que una moza / de mi rumbo vista y calce 
/ y mantenga nada ménos / que á un cabo de provinciales? / Si es tan santa mi señora / como de serlo se aplaude / por más que sude el vecino / y por más que yo trabaje, / se quedará al fin y al cabo / tan honrada como ántes.-Y áun mucho más; que no hay mérito, / como decía mi madre, / en que triunfe la virtud... / cuando nadie la combate. / Si se rinde, buen provecho. / Ella será la culpable» (I, viii).

Estos seductores, frente al don Juan romántico, proceden desde el temor y el cálculo; al mismo tiempo que emprende la seducción de Paula, y que manifiesta su prisa por tenerla, don Cayetano se preocupa por el carácter del marido ( «No tengamos aquí un lance pesado», I, vii) y terminará saliendo del paso del duelo a que le reta el amigo y protector del marido haciendo que un «quídam» finja que lo lleva preso.

El asunto de la seducción, además, no va lejos porque el seductor se jacta ante D. Ramón, el jefe y protector del marido de su propósito y es retado a duelo. Sin embargo, el nuevo error de Paula al juzgar las cortesías de don Ramón («¿Qué fuego ha visto en mis ojos, / que mano se deslizó, / atrevida, aventurera, / que así confunde el amor / con una galantería /propia del genio español / y de la franca amistad / que su esposo me inspiró?», I, xvi), da lugar a una reflexión amarga de Agustín que pone de manifiesto un problema real al que Bretón, por cierto, no dedica ninguna comedia: «Si él me pidiese dinero / como tantos que comercian / con su poder ó su influjo, / oh! sería una bajeza. / Mas codiciar la mujer / de un protegido... es moneda / tan corriente... Así será / nuestra amistad más estrecha; / así brillará en la corte / esa hermosura modesta / que vive oscura, olvidada, / y así tendrán los poetas / satíricos nuevo asunto / donde lucir su agudeza» (II, ii).

Cuentas atrasadas (1841) presenta, como Flaquezas ministeriales, otro caso de una seducción pasada y de la seducida que aparece en la vida del burladorcuando este pretende casarse con una muchacha, exigiendo el pago de las cuentas atrasadas ya que, como dice un personaje: «No hay plazo que no se cumpla ni deuda que no se pague» (IV, iv). El enredo de la obra es grande («iqué lío», dice un personaje, y otro «es caso raro, inédito» y otro más: «otro embrollo»), con dos jóvenes, la hija de la Marquesa y la sobrina de la seducida que fue su ama de cría, de las que durante toda la obra se duda sobre su verdadera identidad. D. Leoncio el seductor es un personaje mal confeccionado por inconstante en sus rasgos y actuación errática. Se presenta pretendiendo a Casimira, hija de la Marquesa, pero valorando con cinismo la belleza de la madre («Aún está pasadera; / pero prefiero á la hija»), da a entender que, tras haber seducido a Sebastiana y haber huido, ha llevado una vida licenciosa («Es fuerte desdicha! / Quiere uno dejar de ser calavera / y no le auxilian!», I, i) y en un monólogo nos informa de que, por encima de la belleza de la joven y de lo pingüe de su dote, lo que más le motiva es hacerse con el título de marqués. Y sin embargo, cuando la mujer burlada lo descubre y acusa, aduce que habría que averiguar quién sedujo a quién, porque él era un joven inexperto y ella una mujer ya madura (lo que también se dirá en El abogado de pobres) y luego se deja vencer con facilidad por el amor paternal al recobrar a la hija que creía perdida, renuncia a la boda que pretendía y da su mano a la mujer que sedujo, a pesar de que, al verla vieja y fea, había prometido hacerse cartujo antes de casarse con ella. La seducción, como en otras comedias, es la cometida bajo promesa de matrimonio. Como dice la Marquesa, «No es seducción dar en falso / palabra de casamiento / a una hija de familia? 
[...] Y sacarla luego / de su hogar tranquilo... / [...] Y llevársela a otro pueblo, / y dejarla allí burlada / con una niña de pecho? [...] Iniquidad! [...] Vileza» (II, vii), y hace que el seductor rebase la condición de calavera para pasar a la de libertino o «monstruo».

La batelera de Pasajes (1842) responde al aprecio del autor por el teatro del Siglo de Oro y presenta por ello otro tipo de seductor, cercano a los galanes de aquellas comedias de capa y espada. Bureba es un valiente capital liberal querido y respetado por sus hombres y apuesto y conquistador con las mujeres. Como en el caso de Rosaura en La vida es sueño, sedujo en su día con promesa de matrimonio a la bella batelera Faustina quien, al verse burlada y abandonada, recorre ahora las guarniciones militares del frente buscando a su burlador para exigirle reparación. El asunto sentimental se complica porque a quien encuentra es a un joven de su pueblo, Pablo, enamorado de ella desde siempre, y la muchacha se debate entre la reparación de su honor y el amor verdadero. La seducción en este caso no se presenta como una felonía inaceptable sino, más bien, como algo comprensible, con cierta permisividad. Siendo él de buena posición, joven, apuesto, valiente militar y mujeriego (por carácter y no por maldad), parece aceptable que seduzca y abandone a una muchacha del pueblo que se creyó sus promesas sin recordar la distancia entre clases y que las promesas se las lleva el viento. Por ello, este caso, tras haberse reparado la honra de la muchacha con un casamiento in articulo mortis, no se llevará al escarmiento del seductor por lo ridículo sino que se solucionará con su muerte en un duelo (por otro asunto de mujeres), sin épica pero también sin bajeza, como si el Tenorio terminara en su enfrentamiento con Avellaneda y Centellas, sin el episodio posterior del arrepentimiento y la salvación.

La escuela de las casadas (1842), comedia en cuatro actos, presenta la figura del seductor que es familiar del marido y aprovecha esa situación para tender sus redes («Yo [...] astuto lobo / con piel de oveja», I, vi), aprovechando la crisis matrimonial, en este caso producida por la sosería de la esposa y la imbecilidad del marido que la deja de lado y busca seducir a otras mujeres sin ver qué consecuencias puede tener su desatención. El procedimiento del seductor es el de galantear a la esposa al tiempo que denigra al marido, mintiendo incluso sobre su infidelidad, para animar a la mujer a pagarle con la misma moneda: «Tanto me punza el agravio»-dirá Carmen- «de aquel hombre fementido, / que grata suena á mi oído / la lisonja de tu labio» (II, iii). Lo que se aprende en esta «escuela», de la mano de su "maestra", Antonia, amiga de Carmen, la esposa, es que se puede ser una esposa como Dios (y la sociedad conservadora) manda sin renunciar por ello a una cierta mundanidad, a unas dosis de coquetería que sirvan para que los maridos no busquen fuera de casa lo que no hallan en ella. Graduada la esposa con alabanzas, el marido reconoce su cortedad y el matrimonio estrecha sus lazos con fuerza. El seductor, por supuesto, recibe el castigo que merece quien codicia a la esposa ajena, siendo rechazado de plano y con desdén por Carmen cuando creía cercana su conquista.

En la comedia en tres actos El editor responsable (1842) Bretón repite el esquema y personajes de Me voy de Madrid. Aquí será Dupré el hipócrita que aprovecha el romanticismo tópico a su favor para seducir a Josefina, crédula obnubilada por el romanticismo, aunque menos que la protagonista de aquella obra ya que tiene mucho más de calculadora, de coqueta que, como si fuera la contrafigura del 
seductor, no tiene inconveniente en jugar con los sentimientos de sus dos pretendientes (figura que Bretón bordó en Una de tantas). Tampoco este Dupré es pintado con la acidez empleada contra don Joaquín, aunque coincida con él en ser un libelista y un adulador del poder y, por supuesto, hipócrita, farsante, taimado y cobarde, y termine la comedia desenmascarado y huyendo. Como seductor tiene poco alcance: tiene prendada a Josefina con su presunta condición de genio pero no desdeña intentar seducir a Ana, muchacha trabajadora y sensata ( «Tentemos otra conquista», dice cuando la ve sola, mientras él espera a la otra). El asunto escabroso ni comienza en este caso porque la muchacha ama en silencio a otro hombre, Gaspar, y da calabazas con gracia al seductor («me ha llamado feo / muy filantrópicamente», dirá, I, viii). Por todo ello, este seductor, como otros del elenco bretoniano, queda en el gremio de los «pícaros», casi simpáticos, más que en el de los canallas.

La Minerva o ;Lo que es vivir en buen sitio! (1844), comedia en un acto, es la plasmación de nuevo del esquema cómico basado en la acumulación de incordios sobre un personaje inocente y de buen corazón. En este caso se trata de Isabel, una joven casada, propietaria de un piso nuevo al que se acaba de trasladar donde será torturada por las visitas en la festividad laica de la Minerva. Como en $E l$ hombre pacífico, sobre Isabel llueven la gorronería y la grosería de una vieja borrachona y enfermiza, de su hija maleducada, de una beatona y el estallido del conflicto entre una vieja encaprichada con el seductor y la novia oficial de este (que le reclama matrimonio como requisito previo a cualquier avance en la relación) cuando los tres se encuentran y se descubre el pastel con, por supuesto, los consiguientes gritos de estas y el bochorno de aquel: «Que es un libertino, un monstruo, / un caballero de industria, / que pretende á dos mujeres / no satisfecho con una, / y con la pobre babea, / y con la rica especula» (escena xvii). A pesar de este retrato, este don Fabricio no pasa de ser un seductor de medio pelo, apocado, en el límite entre ser agresor o víctima de esta vieja furibunda.

Mi dinero y yo (1845) es una mirada algo severa y melodramática al mundo licencioso de la clase alta. Aquí encontraremos a Sabina, una huérfana sencilla, bondadosa, sensata y honesta de quien un marqués, rico reciente, está enamorado sin que le revele a la muchacha su condición de rico y noble. Las necesidades de enredo de la obra llevan a que el marqués enamorado, nuevo curioso impertinente, desee que el amor con que le corresponde Sabina sea puesto a prueba por un rival y, por supuesto, un falso amigo se presta a ello de mil amores y, claro está, pro domo sua. Este es el conde, un libertino serio, hipócrita al acecho que intentará seducir a la muchacha, fiado en su dinero, posición, porte y labia. Su filosofía estriba en la creencia de que el dinero lo compra todo («Acá en el mundo / no hay más Dios que el interés», I, i), incluidas, por supuesto, a las mujeres, y de que el hombre se ha de procurar placer («¿Comete acaso algún crímen / el que á precio de arancel / y á metálico sonante / hoy compra el suntuoso tren / y mañana la hermosura / que quiere lucir en él?», I, i). El sistema de seducción que emplea implica ganarse a la tía de Sabina con la entrega de un dinero de una falsa herencia y requerir «de amores á las primeras de cambio» (II, Xv) a la sobrina que debe resistir la ofensiva de su tía para que haga caso al conde y que llega a falsificar una carta para echar al marqués. El enredo hace que el conde confunda a Sabina con Aurora, bailarina que fue amante del marqués, y le represente la escena del sofá íntegra: piropos, protestas y promesas encendidas de amor (además de alma, vida, 
hacienda y título de condesa), desesperación por la existencia de un rival, juramentos de respetar la inocencia de la dama y, a la vista de la facilidad de la conquista, proposición de rapto, de fugarse juntos, fingimiento teatral seudoromántico de ambos y huida. (II, xxii): un donjuán que encuentra la horma de su zapato y, creyendo ser burlador, es burlado en toda regla por una mujer de similar condición a la suya y que se despeñará desde lo alto de lo que cree sus conquistas («Bravo! En un día le copo / novia y querida. Embriagado / estoy de gloria y de gozo», III. ix) hasta el fondo del bochorno («Si ahora me miro al espejo / veo la cara de un tonto»), aunque la pacificación final haga que todo se olvide y hasta que el conde reconozca que «mujeres como esta / no se compran con dinero».

La hipocresía del vicio (1848) riza el rizo de la comedia satírica sobre los defectos de la sociedad presentando a un protagonista, don Miguel, que se fuerza a ser calavera. Es como si uno de los asistentes a la partida de cartas de don Félix de Montemar o a la cita en la Hostería del Laurel, seducido por el atractivo magnético de estos personajes, decidiera ser como ellos, aunque sus principios y carácter fueran los opuestos a los de aquellos. Esta es la declaración de deseos de don Miguel, el protagonista, que quiere resarcirse de la vida frugal a que le redujo su tío hasta su muerte: «Yo quiero ser calavera / en grande, atroz, temerario, / execrable, otro don Juan / Tenorio, otro Sardanápalo. / ¿Lágrimas? Las que yo cause. / ¿Ley, razón? Vayan al diablo. / El placer sea mi dios / y mi elemento el escándalo». Pero, como venimos viendo, aquí estamos en un mundo burgués, sin épica alguna, y los referentes son «calaveras», hombres juerguistas, disipados e irresponsables, no más. Tampoco la corrupción de don Miguel irá muy lejos porque Bretón ya se encarga de que, en vez de enfangarse en el vicio, se limite a preparar una mascarada en la que actúa de seductor, jugador capaz de poner sobre la mesa el retrato de su dama (como Montemar) y duelista (es tan solo «un tronera» no un «perverso», I, vi) y de que el personaje senior, don Torcuato, amigo del padre de Miguel y de su hermana Felisa (y enamorado de esta), desbarate con su seriedad y sensatez los propósitos del joven desnortado que reconoce estar «corrido de vergüenza», mientras todos lo amonestan por la tontería que acaba de hacer.

La pieza en un acto Los tres ramilletes (1850) vuelve a la comicidad que da la sátira leve, propia de Bretón, convirtiendo en objeto de burla a un «fatuo», «indigesto», «el más tonto de Europa», que alardea de conquistas femeninas para impresionar a un amigo. Este lo castiga contratando a tres tipos que se hacen pasar por maridos de las presuntas seducidas, con el consiguiente mal rato del falso donjuán ya que uno de ellos, capitán, lo reta a duelo; el segundo, boticario, a tomar venenos, y el tercero, un quídam, le propone que su mujer y él se instalen en casa del seductor.

La escuela del matrimonio (1852) evoca desde su título a La escuela de las casadas, pero la índole de una y otra es muy diferente; si la de 1842 era una comedia de que buscaba la risa por los defectos, esta del 52 es una obra seria, muy conservadora, destinada a defender el matrimonio a ultranza contra cualquier amenaza y con muy poca concesión a la risa. La novedad de esta obra en cuanto a la seducción y el adulterio estriba en que el espectador asiste a un intento de seducción serio, verosímil, y que la mujer tentada sí que vacila en ceder, como venganza contra el marido. Emilia, la condesa, mujer que tiene en alta estima su dignidad (aunque - dirá con admiración su marido- provenga «de familia mercantil»), se irrita al saber que el conde tiene un asunto con una belleza limeña. D. 
Federico, amigo del conde, aprovecha el despecho de la mujer para intentar seducirla. Como en Pruebas de amor conyugal, el seductor traspasa la línea que separa la galantería de la seducción, pero aquí la mujer lo nota y se escandaliza: «Perdone usted que le ataje. / Tan fervoroso arrebato / ya de los límites sale de la mistad. / [...] / ¡Y se vende / como amigo inseparable / del Conde. / [...] Eso es infame» A lo que Federico replica: «No lo es; ni aunque lo fuera / debería acriminarme / la que es el único móvil / de mi perfidia, si cabe / perfidia en la adoración / que tributo á sus altares. / Pude yo sacrificar / esta pasión entrañable / á los deberes de amigo, / y encerrarla con cien llaves / en mi pecho, mientras sólo / fueron pecados veniales / los del Conde; mas ¡sufrir / que, haciendo público alarde / de desdeñar á una esposa / de que no es digno, se arrastre / a los piés de vil ramera...» (I, viii).Este es el caso de seducción y de riesgo de adulterio en el que más lejos irá Bretón (cercano ya a los presupuestos estéticos e ideológicos de la «alta comedia»). Cuando Federico ofrece pruebas a Emilia del adulterio de su esposo, ella enajenada («con risa convulsiva») lo apremia a bailar juntos y no rechaza la protesta de amor del seductor, quien rubrica la escena en aparte con un explícito: «Será mía» (II, xiv). Pero tampoco aquí se traspasará la frontera de lo conveniente a la moral burguesa conservadora y católica: Luisa, la «perfecta consorte», defensora acérrima del matrimonio consigue pastorear a los descarriados hasta el redil: «Hay un seductor protervo / que con máscara de amigo / proyecta tu perdición.../ [...] / Don Federico. / No me lo niegues. Sagaz, / perseverante y asiduo, de los excesos del Conde, / que halaga quizá él mismo, / de tu mujeril flaqueza...; / de todo saca partido./ Condesa. No temas. Le oigo... y no más. / Yo evitaré un compromiso...» (III, i). Y, por supuesto, logra también desenmascarar y escarnecer al seductor, a quien denuncia al Conde y a quien hace presenciar la almibarada reconciliación de los esposos hasta retirarse «amostazado» y sin su presa. (III, xix).

También es un fatuo don Joaquín, uno de los parroquianos del café donde se desarrolla la trama de La niña del mostrador (1854), comedia sentimentalizada en dos actos. El primer diálogo de la obra entre él y el criado de la condesa a la que pretende nos informa de que se declaró a ella y fue rechazado porque no creía en la sinceridad de sus afectos («me respondió que ni creía en mis teatrales protestas de amor ni...», I, iii). La gracia del asunto es que va a ser el criado el que exponga su manual de donjuanismo de andar por casa, su «sistema». Ante la pesadumbre de don Joaquín, Gregorio intenta animarlo con una verdad incontestable: «Mujeres hay de sobra», y luego lo alecciona sobre la inconveniencia de enviar cartas porque comprometen y «dan tiempo a pensar la respuesta». Este donjuán de la servidumbre (con algo del criado «gracioso» de las comedias del Siglo de Oro) enamora «siempre por palabras de presente, sazonadas con tal cual guiño y una que otra pantomima» (I, iii) y no se anda por las ramas, trocando, en el peor de los casos, besos por bofetadas. Bien alejado del don Juan (para quien todas las mujeres parecen ser iguales y muy simples), don Joaquín expresa su perplejidad ante ellas: «Diablos de mujeres! ¡Son tan enigmáticas, tan caprichosas...» Pero Gregorio es más pragmático en su fracaso: «Otra me consolará. Ya he echado el ojo a la cocinera, que es moza de chispa y no será tan melindrosa» (I, iii). Una actitud, por cierto, que se presenta invertida en Una de tantas cuando es la protagonista la que, tras descubrirse que acepta el cortejo de dos hombres a la vez, asevera que «Los hombres son mala hierba. / El más fiel no está seguro, / por eso siempre procuro 
/ tener tropa de reserva» La trama se enreda cuando don Joaquín, además de enviar un anónimo infamante sobre la condesa, intenta seducir a la Niña del mostrador para darle celos, galanteando a la muchacha mientras ella sirve en el café y llegando a pedirle una cita, insolencia que la joven corta de raíz, contrariada, dejando al seductor temeroso de que se descubra su intento y avergonzado por su nuevo fracaso. La mala condición del individuo se pone de manifiesto de nuevo por la rudeza con que despacha a un niño huérfano que canta en el café pidiendo limosna. El nuevo intento del seductor se gana la repugnancia de Narcisa y, por su insistencia agresiva, «murmullos de desaprobación» de la concurrencia y, como remate, el desafío a duelo del joven pintor enamorado de la chica del que sale herido, no grave pero sí lo suficiente para su escarmiento. El colofón al castigo se produce cuando, al ver la tarjeta de desafío de don Joaquín, la Condesa reconoce la letra del libelista, con lo que el duelo habrá servido para satisfacer los agravios de las dos mujeres.

Bretón mantiene la figura del seductor hasta su última comedia estrenada, El abogado de pobres (1866), donde vuelve a contraponer el amor sincero con el fingimiento amoroso con fines crematísticos. La seducción, ocurrida tiempo atrás, se añadirá al enredo en el momento oportuno para animar la intriga. El abogado que se ocupa de defender a los pobres es don Ramiro, joven solidario, enamorado en silencio de su prima Carolina, hija de D. Gabriel, rico y ministro, padre y tío afectuoso. La muchacha, enamorada a su vez de su primo, no quiere ser quien primero se declare porque tal papel no corresponde a la mujer en los usos de la época. Por aquellas cosas de las comedias, el padre, que no ve lo que tiene ante los ojos, desea que la joven se case y le ha presentado dos pretendientes: don Fulgencio, periodista, publicista, estadista y fatuo y un marqués, fatuo, tronado, badulaque y títere, que en pasado sedujo a una criada. En el relato que Carolina hace de la petición de matrimonio por parte de don Fulgencio parecen quedar ecos del Tenorio: «yo me dejé alucinar / por la estudiada pasión / y hueca verbosidad / con que postrado á mis pies / me pidió el sí conyugal» (I, iii), aunque dice haberlo hecho por querer librarse del marqués (a quien avalaba una deuda de gratitud de su padre) y haberse arrepentido al instante «porque, petulante y sandio, / á la menos perspicaz / hubiera hecho conocer / con su cháchara vulgar / que todo es cálculo en él / y aparato teatral» (I, iii). Despedido este fantoche tras haber sabido que el ministro, dimitido, no iba a otorgarle nombramiento alguno, la despedida del otro se hace por la aparición sorpresiva de la criada a la que sedujo tiempo atrás en su casa. Esta seducción doméstica, de señoritos a criadas ingenuas o interesadas es, como dice Ramiro: «Lo de siempre» De forma cómicamente premiosa, Catuja, la seducida, relata el proceso conocido: el acoso del señorito, la resistencia de la muchacha, las promesas de matrimonio, la seducción, el embarazo, la huida del seductor, la vergüenza y dificultades de la burlada. El marqués, apremiado por el ministro, Ramiro y Carolina, confiesa que: «Juro al concilio de Trento / que de mi conducta aleve / me sonrojo y me arrepiento; / mas si la culpa no es leve / mayor es el escarmiento. / Sin que judicial edicto / venga a aumentar mi conflicto, / la pretensión desamparo- / jay dolor! -y me declaro / reo confeso y convicto» (III, ii). Pero aún intenta minimizar lo que hizo, comparándolo con el amor que dice sentir por Carolina: «Capricho fue aquel, sí tal, / pasajero, y por el cual / más la lástima que el odio / merezco; fue... un episodio, / y esta es la acción principal»; declaración que no lo libra del desenlace previsto: 
«echarme, sin enlace, / por la puerta de los carros / y castigar mis desbarros / con un requiescat in pace» (III, iii). Pero el asunto no termina ahí porque hay que anudar el cabo suelto que es Catuja. Esta, que ha estado escuchando exige reparación a su seductor, apoyada por don Gabriel, el ministro («Con la honra / de una mujer no se juega») y el seductor, aunque se resiste (exige pruebas, plantea la duda de quién sedujo a quién, sostiene que no puede casarse con una mujer de la plebe) termina aceptando, exasperado, compensar económicamente a la mujer con tal de no verla más en su vida.

\section{El cambio de papel de la mujer en las relaciones afectivas}

De la Risa a la risa. La Risa, la vitalidad de los fabliaux o de la comedia erótica quedan fuera en estas comedias costumbristas satíricas teñidas de conservadurismo en su mayor parte que se quedan en la risa justo, al revés, a costa del que rompe las normas, del que encarna la vitalidad.

Y sin embargo, de forma indirecta, Bretón homenajea uno de los componentes ideológicos del Romanticismo mientras parece atacarlo: la sinceridad de los afectos. Como hemos visto, en la mayor parte de comedias tanto los seductores más malévolos como los chisgarabises coinciden en la hipocresía con que dicen su amor y en el engaño, el polo opuesto a la sinceridad y la vehemencia de los amadores de los dramas románticos, cuya nobleza queda en los amadores y novios de las muchachas decentes.

El castigo del seductor es, por lo general y como se ha visto, el que se descubra su verdadera condición y con ello quede avergonzado y pierda lo que ambiciona. Pero hay algo más que apunta en estas comedias y, a pesar de su sencillez, las hace algo complejas. No cabe duda de que el mito de Don Juan supone una relación problemática con la mujer (Becerra, 1997: 90). Lo que se ve en estas comedias es que la mujer está cambiando y se enfrenta ahora a la seducción de forma activa, unas veces aleccionada sobre las trampas de un falso romanticismo y otras, investida de una dignidad y personalidad grandes y autónomas que les permiten rechazar a petulantes, fatuos, engreídos o, simplemente, malvados. Además, tras el impulso inicial, son ellas quienes llevan la iniciativa: tienen la posición, el dinero y la iniciativa. No son donjuanes inversos porque no son cínicas seductoras, pero sí son desenmascaradoras; comienzan, incluso, a plantear la separación matrimonial y el divorcio como solución al desamor y hasta alguna de ellas puede llegar a decir «siempre / aborrecí la coyunda matrimonial», como la Gervasia de La escuela de las casadas que también tiene claro que buena parte de la infelicidad de las mujeres malqueridas la tienen ellas mismas: «Estúpida»-dice a su sobrina«Echarse por tierra / cuando podría... ¡Así abusan / los hombres de su poder! / Así gallean y triunfan! / [...] / Esa causa no es tuya / solamente. / [...] Es de todo el bello sexo».

\section{Referencias bibliográficas}

Argullol, Rafael (1982): El Héroe y el Único. El espíritu trágico del Romanticismo. Madrid, Taurus. BECERrA SuÁreZ, Carmen (1997): Mito y literatura (Estudio comparado de Don Juan). Vigo, Servicio de Publicacións da Universidade de Vigo. 
Bretón DE LOS Herreros, Manuel (1883-1884): Obras. Madrid, Imprenta de Miguel Ginesta. Tomo I, II y III (1883); Tomo IV (1884).

CASAlduero, Joaquín (1974): «El teatro en el siglo XIX», en José María DíEz BorQue, coord., Historia de la literatura española, vol. III: siglos XIX y XX. Madrid, Guadiana.

CRESPO MATElláN, Salvador (1979): La parodia dramática en la literatura española. Salamanca, Ediciones Universidad de Salamanca.

DíEZ TABOADA, Juan Ma (1997): «La alta comedia», en Víctor GARCÍA DE LA CONCHA, dir., y Guillermo CARNERO, coord. Siglo XIX, Historia de la literatura española. Madrid, Espasa Calpe.

MARRAST, Robert, (1989): José de Espronceda y su tiempo. Literatura, sociedad y política en tiempos del romanticismo. Trad. de Laura Roca. Barcelona, Crítica.

Muro, Miguel Ángel (2003): «La comedia: De Bretón de los Herreros a Tamayo y Baus», en Javier Huerta CAlvo, dir., y Fernando Doménech Rico y Emilio Peral VeGa, coords., Historia del teatro español. II. Del siglo XVIII a la época actual. Madrid, Gredos, 1943-1975.

Rodríguez AdRAdos, Francisco (1972): Fiesta, comedia y tragedia. Sobre los orígenes griegos del teatro. Barcelona, Planeta.

SERrano, Carlos (1995): «Don Juan Tenorio y sus parodias: el teatro como empresa cultural», en Javier Blasco Pascual, Ricardo DE la Fuente BALlesteros y Alfredo Mateos Paramio, eds.: Actas del congreso sobre José Zorrilla. Una nueva lectura. Valladolid, Fundación Jorge Guillén y Universidad de Valladolid. 